\title{
THE
}

\section{Observations of the Subtropical Mode Water Evolution from the Kuroshio Extension System Study}

Bo Qiu

Peter Hacker

Shuiming Chen

Kathleen A. Donohue

University of Rhode Island, kdonohue@uri.edu

D. Randolph Watts

University of Rhode Island

See next page for additional authors

Follow this and additional works at: https://digitalcommons.uri.edu/gsofacpubs

\section{Citation/Publisher Attribution}

Qiu, B., Hacker, P., Chen, S., Donohue, K. A., Watts, D. R., Mitsudera, H., Hogg, N. G., \& Jayne, S. R. (2006). Observations of the Subtropical Mode Water Evolution from the Kuroshio Extension System Study. Journal of Physical Oceanography, 36, 457-473. doi: 10.1175/JP02849.1

Available at: https://doi.org/10.1175/JP02849.1

This Article is brought to you for free and open access by the Graduate School of Oceanography at DigitalCommons@URI. It has been accepted for inclusion in Graduate School of Oceanography Faculty Publications by an authorized administrator of DigitalCommons@URI. For more information, please contact digitalcommons-group@uri.edu. 


\section{Authors}

Bo Qiu, Peter Hacker, Shuiming Chen, Kathleen A. Donohue, D. Randolph Watts, Nelson G. Hogg, and Steven R. Jayne

This article is available at DigitalCommons@URI: https://digitalcommons.uri.edu/gsofacpubs/410 


\title{
Observations of the Subtropical Mode Water Evolution from the Kuroshio Extension System Study
}

\author{
Bo Qiu, Peter Hacker, and Shuiming Chen \\ Department of Oceanography, University of Hawaii at Manoa, Honolulu, Hawaii \\ Kathleen A. Donohue and D. Randolph Watts \\ Graduate School of Oceanography, University of Rhode Island, Narragansett, Rhode Island \\ Humio Mitsudera \\ Graduate School of Environmental Earth Science, University of Hokkaido, Sapporo, Japan \\ Nelson G. Hogg and Steven R. Jayne \\ Woods Hole Oceanographic Institution, Woods Hole, Massachusetts
}

(Manuscript received 24 January 2005, in final form 17 July 2005)

\begin{abstract}
Properties and seasonal evolution of North Pacific Ocean subtropical mode water (STMW) within and south of the Kuroshio Extension recirculation gyre are analyzed from profiling float data and additional hydrographic and shipboard ADCP measurements taken during 2004. The presence of an enhanced recirculation gyre and relatively low mesoscale eddy variability rendered this year favorable for the formation of STMW. Within the recirculation gyre, STMW formed from late-winter convection that reached depths greater than $450 \mathrm{~m}$ near the center of the gyre. The lower boundary of STMW, corresponding to $\sigma_{\theta} \simeq 25.5$ $\mathrm{kg} \mathrm{m}^{-3}$, was set by the maximum depth of the late-winter mixed layer. Properties within the deep portions of the STMW layer remained largely unchanged as the season progressed. In contrast, the upper boundary of the STMW layer eroded steadily as the seasonal thermocline deepened from late April to August. Vertical eddy diffusivity responsible for this erosion was estimated from a budget analysis of potential vorticity to be in the range of $\sim 2-5 \times 10^{-4} \mathrm{~m}^{2} \mathrm{~s}^{-1}$. The latitudinal extent of the STMW formation was narrow, extending from $30^{\circ} \mathrm{N}$ to the Kuroshio Extension jet near $35^{\circ} \mathrm{N}$. South of $30^{\circ} \mathrm{N}$, STMW did not form locally but was transported from the recirculation gyre by lateral induction.
\end{abstract}

\section{Introduction}

North Pacific Ocean subtropical mode water (STMW), first identified by Masuzawa $(1969,1972)$ as a $16^{\circ}-17^{\circ} \mathrm{C}$ thermostad lying above the permanent thermocline in the northwestern subtropical gyre of the North Pacific, forms during winter convection. Like mode waters in other subtropical gyres of the World Ocean, the North Pacific STMW is found on the equatorward side of the Kuroshio and its extension, the Kuroshio Extension (KE). Characterized by a layer of

Corresponding author address: Dr. Bo Qiu, Department of Oceanography, University of Hawaii at Manoa, 1000 Pope Road, Honolulu, HI 96822.

E-mail: bo@soest.hawaii.edu minimum potential vorticity (PV), STMW can be detected over a wide geographic domain from $130^{\circ} \mathrm{E}$ to the date line and from the Kuroshio-KE to the subtropical front. STMW has been extensively studied (e.g., Suga et al. 1989; Bingham 1992; Suga and Hanawa 1995; Yasuda and Hanawa 1997), and an updated and comprehensive review of STMW may be found in Hanawa and Talley (2001).

In recent years, a renewed interest in the formation and erosion processes of STMW has arisen. STMW serves as a heat reservoir: it is a direct product of wintertime air-sea interaction but is sheltered from surface processes for a significant duration of time. This sequestered heat reservoir can reemerge through vertical entrainment and/or lateral induction (i.e., horizontal 
temperature advection across the base of a sloping mixed layer), modulating local sea surface temperatures (SSTs) of subsequent winters, or can be advected to remote regions by ocean circulation.

It is worth emphasizing that STMW formation and its subsequent evolution depend not only on atmospheric forcing but also on oceanic conditions, such as the preexisting density stratification and mesoscale eddy activity. For example, Yasuda and Hanawa (1997) conduct a composite temperature data analysis and find that part of the STMW changes observed after the mid-1970s is likely caused by changes in the zonal heat advection of the Kuroshio. By analyzing historical CTD/XBT data and by conducting numerical experiments using a bulk mixed layer model, Qiu and Chen (2006) find that the decadally varying STMW formation is closely related to the dynamic state of the KE system. Less STMW is formed when the KE system is in an unstable state, during which high regional eddy variability infuses the high-PV KE water into the recirculation gyre, increasing the upper-ocean stratification and hindering the development of a deep-winter mixed layer. A stable KE system, on the other hand, favors the maintenance of a weak stratification, leading to a deep-winter mixed layer and formation of a thick STMW layer.

While many aspects of STMW have been described in the past through analyses of historical hydrography, our understanding regarding the detailed dynamic and thermodynamic processes of STMW formation and erosion remains fragmentary. One goal of the Kuroshio Extension System Study (KESS) field program is to clarify processes that govern the temporal variability of STMW and to then determine its impact upon SST and surface mixed layer signals. (Complete scientific objectives of KESS can be found online at http://www.gso. uri.edu/kess.) During the first KESS cruise in AprilJune 2004, 20 Apex profiling floats were deployed and numerous CTD casts and shipboard acoustic Doppler current profiler (ADCP) measurements were conducted. This paper analyzes these KESS measurements along with satellite altimetry sea surface height (SSH) measurements and profiling float data from the Japanese Argo program (Oka and Suga 2003) in order to achieve two objectives. The first is to provide a synoptic description of STMW as observed in May 2004. Detailed structures of STMW near the core of the KE jet and the connections between the observed STMW and the late-winter SST field are explored. The second is to examine the temporal evolution of STMW, especially the role played by vertical eddy diffusion in the erosion of STMW during the spring-to-fall seasons. Contrasts will be made between the STMWs detected inside and south of the recirculation gyre.
Because the characteristics of STMW depend on the dynamic state of the $\mathrm{KE}$ and its recirculation gyre, it is helpful to comment on the large-scale circulation pattern of the KE system, which is known to undergo large-amplitude decadal changes (Miller et al. 1998; Deser et al. 1999; Qiu 2003). Over the last decade, the KE jet has moved from a highly unstable state with a weak southern recirculation gyre and temporally varying paths in 1995-98 to a highly stable state with steady path since 2002. As shown by the SSH pattern in Fig. 1, the two meanders of the KE jet remained largely stationary in 2004, with the southern circulation composed of two fully developed anticyclonic subgyres. This is in sharp contrast to the state of the KE system during 1995-98 when the southern recirculation gyre was weak and the downstream anticyclonic subgyre was barely discernible (see Fig. 2 in Qiu and Chen 2005). Our analysis will show that a strengthened southern recirculation and suppressed mesoscale eddy variability in the region made 2004 a favorable year for the formation of STMW.

\section{KESS'04 surveys}

The first KESS cruise was conducted by the Research Vessel (R/V) Thompson from 24 April to 19 June 2004. During the cruise 46 current and pressure recording inverted echo sounders (CPIES), 6 moored profiler (MP) moorings, and 20 Apex profiling floats were deployed (Fig. 1). In addition, the Pacific Marine Environmental Laboratory (PMEL) Kuroshio Extension Observatory (KEO) flux mooring was set up at $32.5^{\circ} \mathrm{N}$ and $144^{\circ} \mathrm{E}$, and numerous CTD casts and deepreaching $(\sim 750 \mathrm{~m}) \mathrm{ADCP}$ transects crossing the $\mathrm{KE}$ jet were accomplished.

Figure 2 shows the trajectories of the 20 profiling floats since their deployment in the KE recirculation gyre region. With the recirculation gyre being strong and relatively stable in 2004, most of the floats are seen to be trapped in the recirculation gyre south of the first quasi-stationary meander of the KE jet. The KESS Apex floats conduct the temperature-salinity $(T-S)$ measurements every 5 days as they rise from the 1500-m parking depth. The measurements have a vertical resolution of $5 \mathrm{~m}$ in the surface $100-\mathrm{m}$ layer, $10 \mathrm{~m}$ in the $100-400-\mathrm{m}$ layer, $30 \mathrm{~m}$ in the $400-1000-\mathrm{m}$ layer, and $100 \mathrm{~m}$ in the $1000-1500-\mathrm{m}$ layer. As of 31 December 2004, $913 T-S$ profiles have been collected by these 20 floats, and detailed information about the data and profile locations is available online (http://www.soest. hawaii.edu/snol). To complement the KESS profiling float data, we also include in this study data from an 


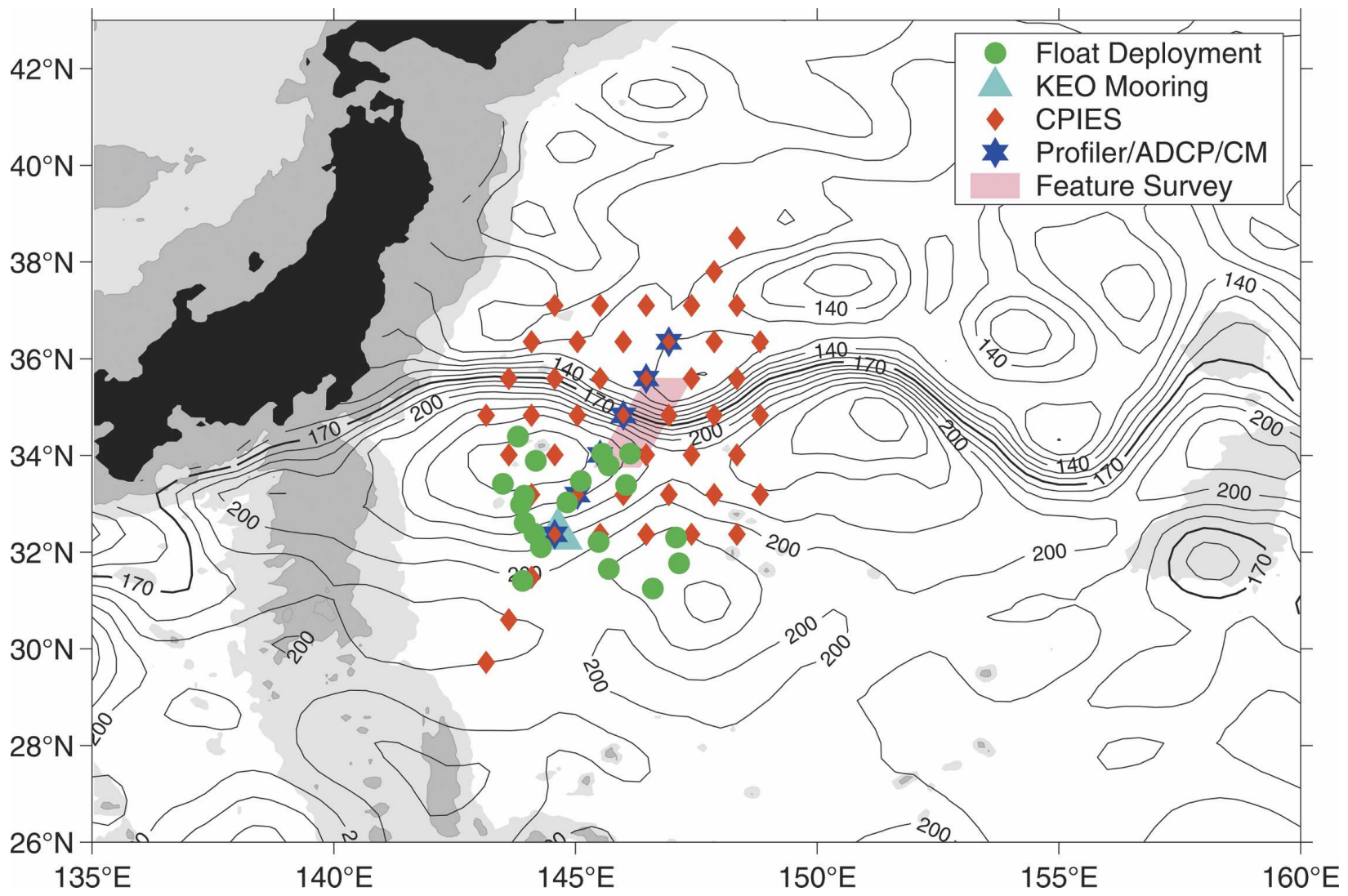

FIG. 1. KESS observing array deployed in May-June 2004. Contours denote the SSH field from satellite altimetric data (cm) and Teague et al. (1990). Light and dark gray shadings denote the 2000- and 4000-m depth contours, respectively. Major bathymetric features in the region include the Izu Ridge along $140^{\circ} \mathrm{E}$ and the Shatsky Rise around $159^{\circ} \mathrm{E}$.

additional eight profiling floats that are in the domain and period of our interest from the Japanese Argo program (Oka and Suga 2003). For all of the profiling data, a delayed-mode quality control is conducted following a procedure similar to that proposed by Wong et al. (2003).

To provide a synoptic view of the distribution and properties of the STMW, the float-derived profiling $T-S$ data are combined in this study with the 125 highdensity CTD casts collected during leg 1 of the KESS cruise from 27 April to 29 May 2004. As shown in Fig. 3 , the leg-1 CTD casts covered a broad area of the KE and its southern recirculation gyre; 58 of these casts were clustered in the trough region between the KE's two quasi-stationary meanders. This spatially dense CTD survey was designed specifically to study mesoscale-driven, cross-frontal flows, and features pertinent to STMW will be discussed in this paper. In conjunction with the CTD casts, shipboard ADCP data along the transects across the $\mathrm{KE}$ jet will also be analyzed for concurrent velocity information.

Last, satellite altimetry data are used in this study to capture the time-varying surface dynamic signals of the $\mathrm{KE}$ jet and its southern recirculation gyre. For this purpose, we use the global SSH anomaly dataset compiled by the Collecte, Localisation, Satellites (CLS) Space Oceanographic Division of Toulouse, France. The dataset merges the Ocean Topography Experiment (TOPEX)/Poseidon, Jason-1, and European Remote Sensing Satellite (ERS)-1/-2 along-track SSH measurements and has an improved capability of detecting mesoscale SSH signals (Le Traon and Dibarboure 1999; Ducet et al. 2000). The CLS SSH anomaly dataset has a 7 -day temporal resolution and a $1 / 3^{\circ} \times 1 / 3^{\circ}$ spatial resolution. Using the climatological surface dynamic height data of Teague et al. (1990) as the mean SSH, the absolute SSH field (which will be referred to as the $\mathrm{SSH}$ field for brevity) is simply the sum of the mean and anomalous SSH data.

\section{Synoptic survey of STMW in May 2004}

Availability of the large amount of profiling float $T-S$ data and CTD casts during May of 2004 provides us with a rare opportunity to examine the STMW proper- 

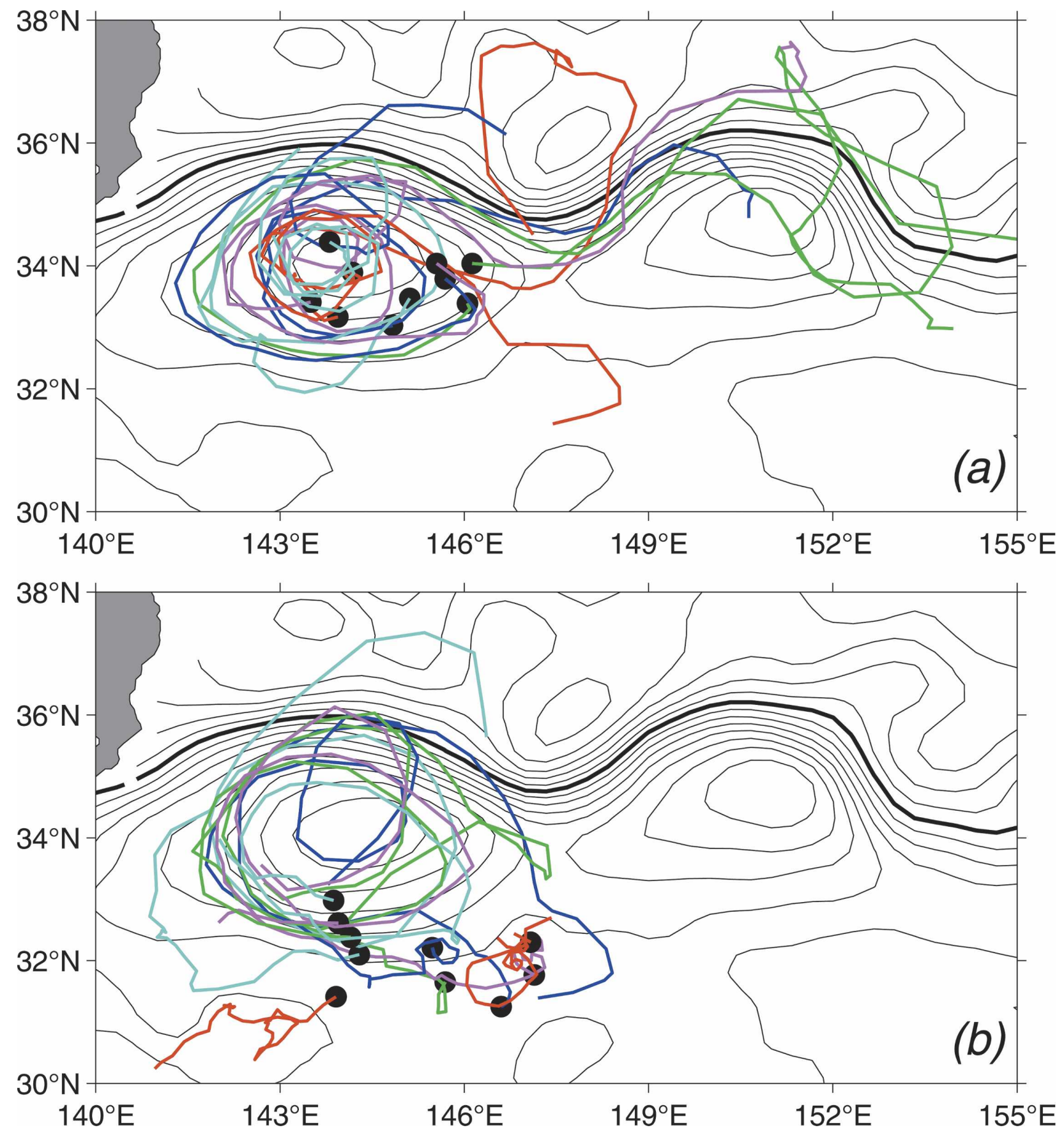

FIG. 2. KESS Apex float trajectories (colored lines) with black dots indicating deployment locations. The 20 floats were deployed in the period from 28 Apr to 18 Jun 2004, and their trajectories shown here end on 31 Dec 2004. The 10 floats deployed (a) north and (b) south of $33^{\circ} \mathrm{N}$ are shown. Contours indicate the SSH field averaged in April-November 2004. Contour intervals are $0.1 \mathrm{~m}$ and the thick black lines denote the $1.7-\mathrm{m}$ contours.

ties on a synoptic time scale. To provide a context for exploring the STMW, we plot in Fig. 4 the meridional distributions of potential temperature $(\theta)$, salinity $(S)$, potential density $\left(\sigma_{\theta}\right)$, and potential vorticity $(Q)$ along a transect across the KE (see closed triangles in Fig. 3 for the stations and the SSH field in May of 2004). Here, the PV (see Talley 1988) is defined by

$$
Q \equiv-\frac{f}{\rho} \frac{\partial \sigma_{\theta}}{\partial z},
$$




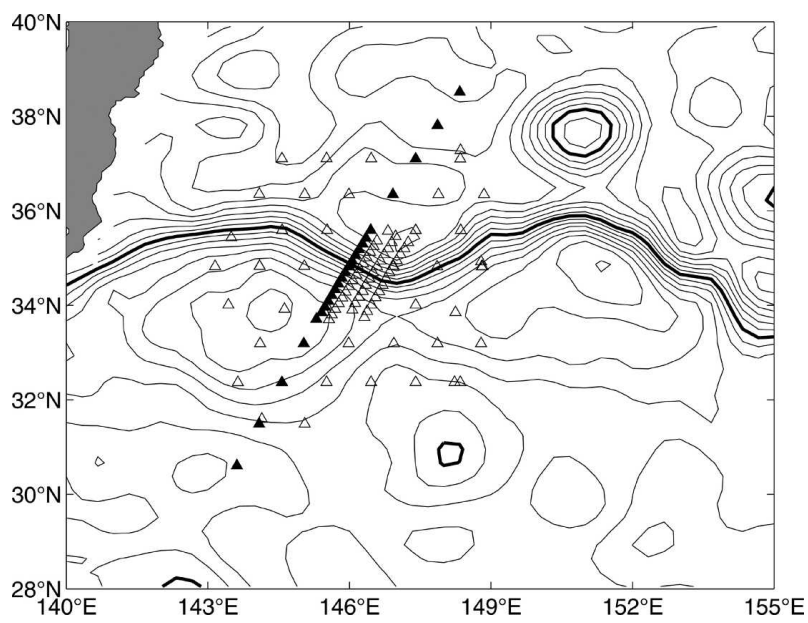

FIG. 3. Stations of CTD casts collected during the KESS leg-1 cruise in 27 Apr-29 May 2004. Casts with closed triangles are used in Fig. 4 to show vertical distributions of $\theta, S, \sigma_{\theta}$, and PV. Contours indicate the SSH field in May 2004. Contour intervals are $0.1 \mathrm{~m}$, with the thick black lines denoting the $1.7-\mathrm{m}$ contours.

where $f$ is the Coriolis parameter and $\rho$ is the water density.

In Fig. 4, the steep fronts of $\theta, S$, and $\sigma_{\theta}$ associated with the baroclinic KE jet are located around $34.7^{\circ} \mathrm{N}$. The $12^{\circ} \mathrm{C}$ isotherm (or the $26.0 \sigma_{\theta}$ isopycnal) at the $300-\mathrm{m}$ depth have been used in the past to indicate the axis of the KE jet (e.g., Mizuno and White 1983). This isotherm (or isopycnal) can be seen in Fig. 4 to represent the KE front very well. Notice that a narrow PV maximum with a width on the order of $50 \mathrm{~km}$ exists along the KE front (see Fig. 4d). Indeed, this PV maximum roughly follows the $12^{\circ} \mathrm{C}$ isotherm in both the subtropical and subpolar regions away from the KE front.

South of the high-PV KE front, a band of water with PV less than $2 \times 10^{-10} \mathrm{~m}^{-1} \mathrm{~s}^{-1}$ can be seen to occupy the layer between the 100- and 450-m depths. This is the STMW of interest to this study. In addition to being a PV minimum layer, Fig. 4 reveals that STMW is also a layer of thermostad $\left(16.0^{\circ}-18.0^{\circ} \mathrm{C}\right)$, halostad $(34.70$ $34.85 \mathrm{psu})$, and pycnostad (25.2-25.5 $\sigma_{\theta}$ ). These characteristic $\theta, S$, and $\sigma_{\theta}$ values agree well with those reported in previous STMW studies (e.g., Hanawa and Talley 2001; Suga et al. 1989). Notice that low-PV waters with $Q<2 \times 10^{-10} \mathrm{~m}^{-1} \mathrm{~s}^{-1}$ exist also on the northern side of the KE jet. They are, however, easy to distinguish from STMW because their water temperatures are typically colder than $8^{\circ} \mathrm{C}$.

While STMW has been known to be formed by convective mixing in late winter south of the KE (Hanawa 1987), its northern limit with respect to the KE jet remains obscure. Information from the KESS shipboard
ADCP measurements in conjunction with the CTD surveys helps in this regard. Figure 5a shows the downstream velocity of the KE jet along the transect we just discussed (to emphasize the connection between the KE jet and STMW, only the region of high-resolution CTD casts is presented). The maximum speed is about $2.0 \mathrm{~m} \mathrm{~s}^{-1}$, and the core of the KE jet near the surface is located at $34.8^{\circ} \mathrm{N}$, shifting southward with increasing depth. Because of the existence of the southern recirculation gyre, the $\mathrm{KE}$ jet has a broader width to the south of the jet core than to the north. Superimposed on Fig. 5a are the white PV contours delineating the presence of STMW: thick and thin white lines denote $Q=2 \times 10^{-10}$ and $1 \times 10^{-10} \mathrm{~m}^{-1} \mathrm{~s}^{-1}$, respectively. Interestingly, the northern limit of STMW is seen to extend deep into the high-velocity core $\left(U>1.0 \mathrm{~m}^{-1}\right.$ $\mathrm{s}^{-1}$ ) of the KE jet. An estimate from the SSH map in Fig. 3 indicates that the eastward throughflow of the $\mathrm{KE}$ jet south of its axis is about $0.6^{\circ}$ wide. The juxtaposition of low-PV water with the outer KE core suggests that part of the STMW observed north of $\sim 34.2^{\circ} \mathrm{N}$ is likely to be advected to the downstream KE region, instead of recirculating in the southern recirculation gyre.

The PV defined in Eq. (1) neglects the contribution from the relative vorticity of the circulation. To what extent does this affect the STMW signals? To address this question, we plot in Fig. 5b the ratio of relative vorticity $\zeta=-\partial U / \partial n$ over $f$, where $U$ is the downstream velocity and $n$ denotes the cross-stream direction. The largest ratio, with $\zeta / f>1$, is found on the northern side of the surface KE jet. On the southern side of the jet, $|\zeta| / f$ is commonly smaller than 0.4 . The thick (thin) white lines in Fig. 5b show the same PV contours as in Fig. 5a, except that the planetary potential vorticity $Q$ in this case is replaced by $Q^{\prime}=-(f+\zeta) \partial \sigma_{\theta} / \partial z / \rho$. As compared with Fig. 5a, the low-PV STMW layer in Fig. $5 \mathrm{~b}$ is widened near the high-velocity core of the KE jet. This widening, however, is spatially confined; the effect of $\zeta$ is mostly negligible for the STMW signals south of $34.2^{\circ} \mathrm{N}$.

In the high-shear region immediately north of the $\mathrm{KE}$ core, relative vorticity makes an important contribution to the PV signal. As shown in Fig. 5c (which compares the cross-stream PV values averaged in the STMW layer of $100-400 \mathrm{~m}$ based on $Q$ versus $Q^{\prime}$ ), inclusion of $\zeta$ increases the core's PV value from $4 \times 10^{-10}$ to $7 \times$ $10^{-10} \mathrm{~m}^{-1} \mathrm{~s}^{-1}$. This large value of PV associated with the cyclonic side of the KE jet core has been found to affect the precooling season stratification in the recirculation gyre and the formation of STMW when the KE jet is in an unstable state (Qiu and Chen 2006).

To gain a better view of how STMW is distributed 

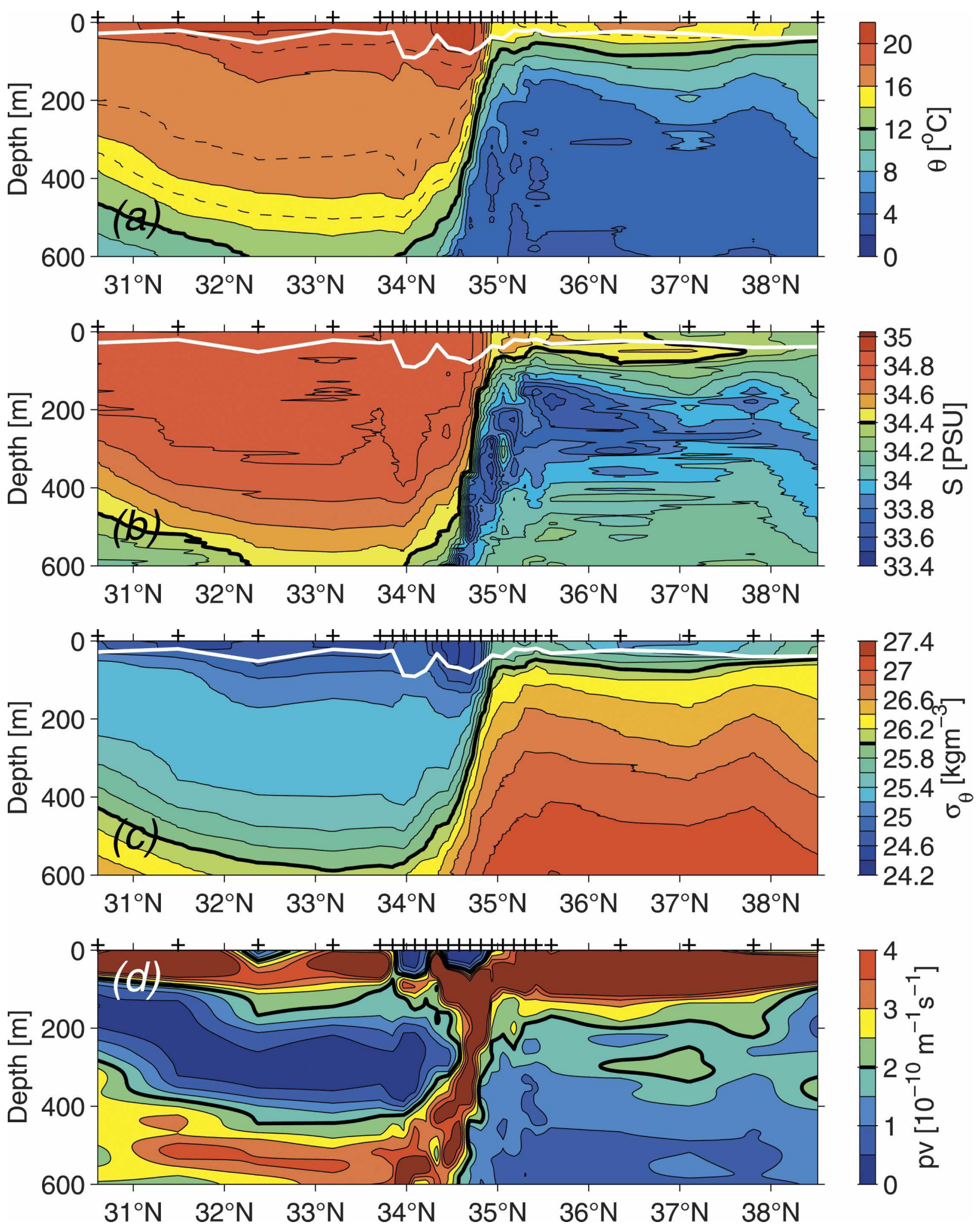

FIG. 4. (a) Potential temperature, (b) salinity, (c) potential density, and (d) potential vorticity distributions along a KESS leg-1 transect across the KE system. Crosses at top of each panel indicate the CTD casts whose geographical locations are shown by closed triangles in Fig. 3. White contours in (a)-(c) denote the mixed later depth, defined as the depth at which $\sigma_{\theta}$ increases by $0.125 \mathrm{~kg} \mathrm{~m}^{-3}$ from its surface value. Thick contours indicate the isopleths of (a) $T=12^{\circ} \mathrm{C}$, (b) $S=34.4 \mathrm{psu}$, (c) $\sigma_{\theta}=26.0$, and (d) $\mathrm{PV}=2 \times 10^{-10}$ $\mathrm{m}^{-1} \mathrm{~s}^{-1}$, respectively. 

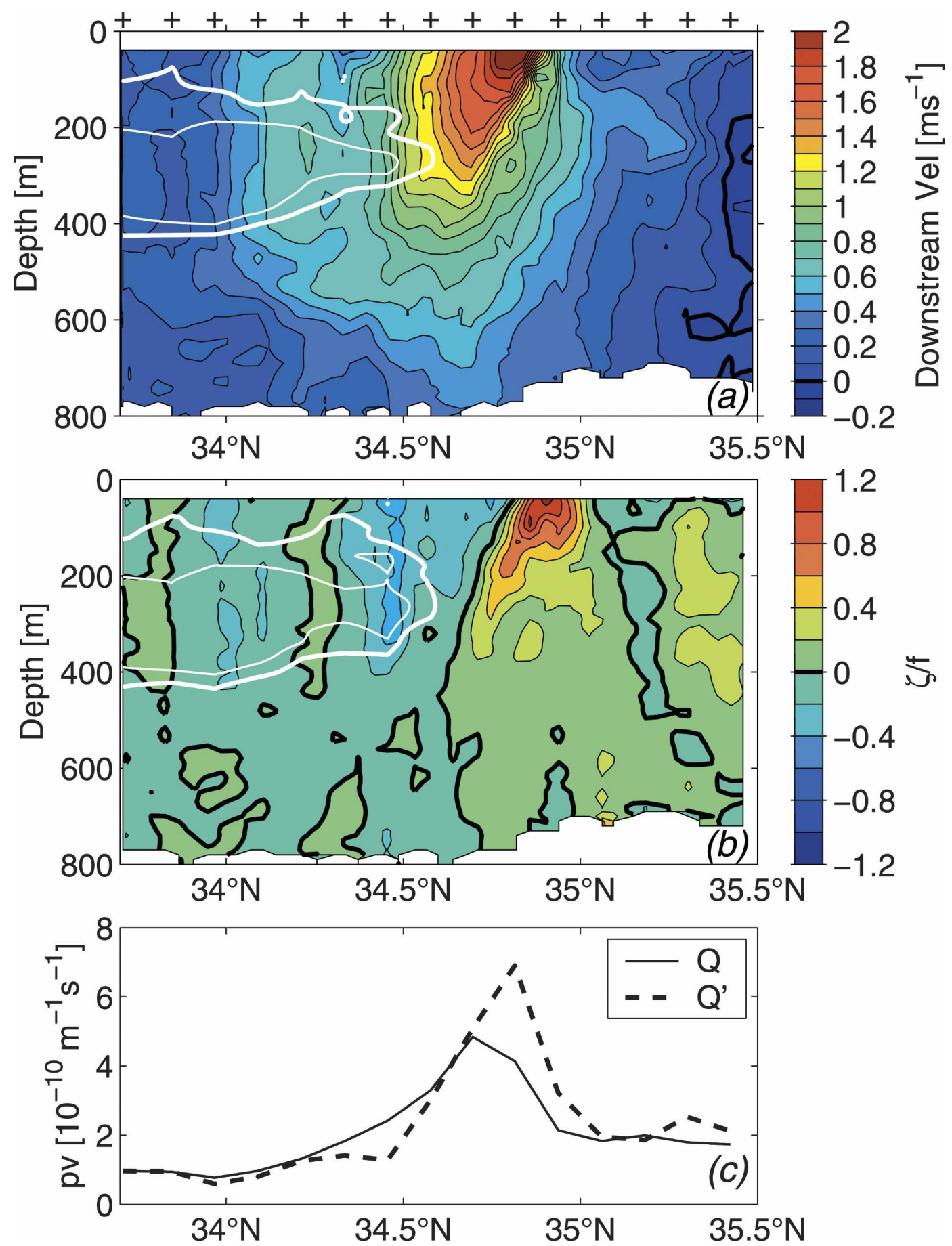

FIG. 5. (a) Downstream velocity measured by shipboard ADCP along the closely spaced CTD section shown in Fig. 3 (closed triangles). Here the angle of the downstream direction ( $138^{\circ}$ from the north) is given by the maximum 50-250-m depth-averaged velocity vector. The CTD stations are indicated by crosses at top of the panel. Thick (thin) white lines indicate the PV $=2(1) \times 10^{-10} \mathrm{~m}^{-1} \mathrm{~s}^{-1}$ isopleths associated with STMW (the same contours are shown in Fig. 4d). (b) Ratio of the relative vorticity $\zeta$ over $f$. Thick (thin) white lines indicate the $\mathrm{PV}=2(1) \times 10^{-10}$ $\mathrm{m}^{-1} \mathrm{~s}^{-1}$ isopleths that include the effect of $\zeta$. (c) PV values averaged in the depth range of 100-400 m. Solid (dashed) line denotes the values without (with) the effect of $\zeta$. 

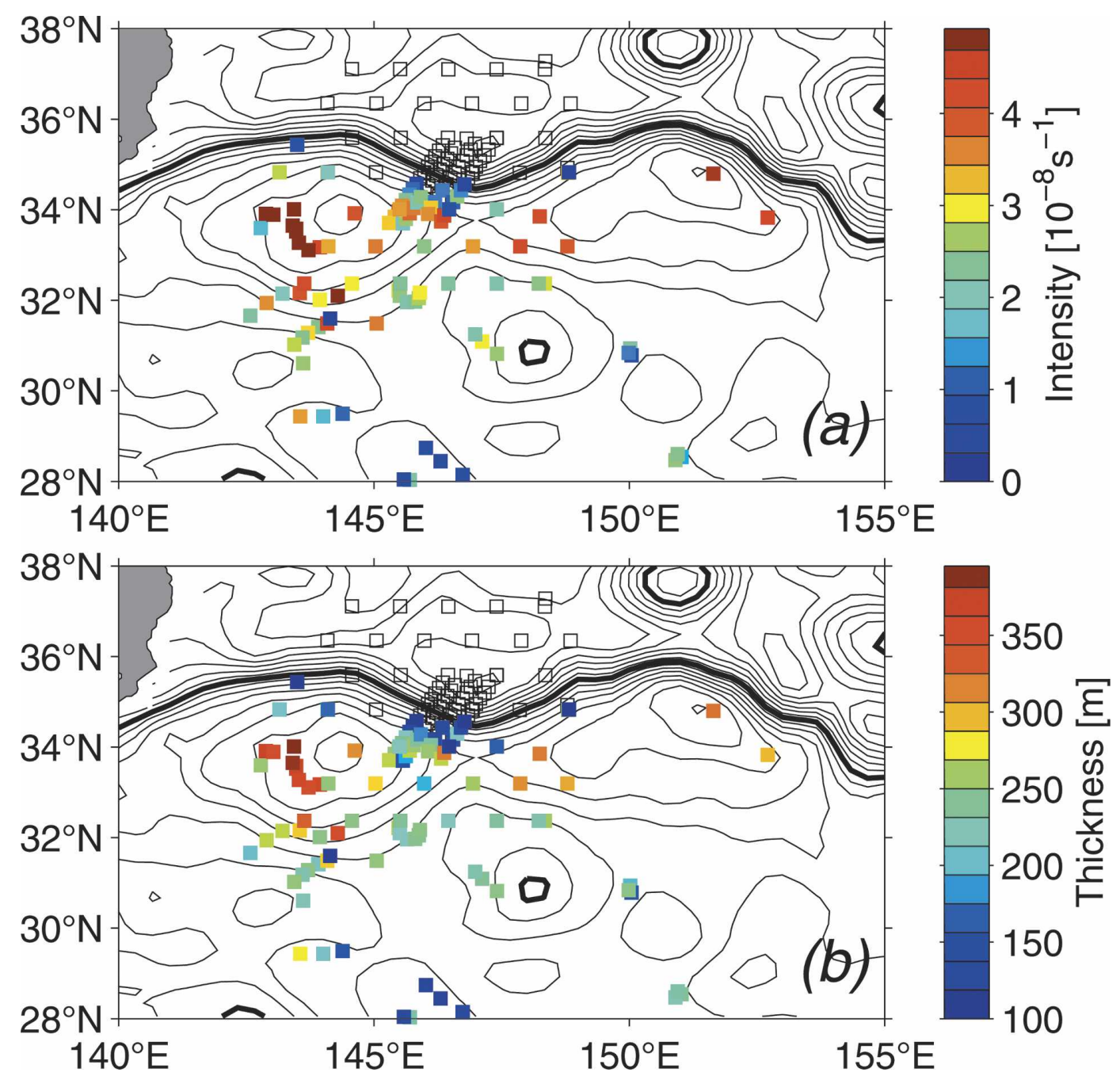

FIG. 6. (a) Intensity and (b) thickness of STMW estimated from available CTD casts and profiling $T-S$ data in May 2004. Open squares indicate sites where no STMW is detected. Contours indicate the SSH field in May 2004. Contour intervals are $0.1 \mathrm{~m}$, with the thick black lines denoting the $1.7-\mathrm{m}$ contours.

horizontally in the KE region, we plot in Figs. 6a and 6b its intensity and thickness, respectively, based on the KESS leg-1 CTD data and the profiling float $T-S$ data obtained during May 2004. Here, the STMW intensity is defined as the PV anomaly (relative to $Q_{o}=2 \times$ $10^{-10} \mathrm{~m}^{-1} \mathrm{~s}^{-1}$ ) integrated vertically within the STMW layer:

$$
I=\int_{z_{2}}^{z_{1}}\left[Q_{o}-Q(z)\right] d z,
$$

where $z_{1}$ and $z_{2}$ are the upper and lower boundaries encompassing the STMW layer with $Q<Q_{o}$. For profiles where no STMW is detected, they are indicated in Fig. 6 as open squares. In general, STMW is observed to be more intense toward the centers of the anticy- clonically recirculating regions than along their edges (Fig. 6a). Relatively weak STMW is found in a cyclonic eddy centered at $30.5^{\circ} \mathrm{N}$ and $148^{\circ} \mathrm{E}$, and there exists a general trend for STMW to become weaker as one moves equatorward. The tendency that STMW is better developed in anticyclonic areas than in cyclonic areas is consistent with Uehara et al. (2003) who found that anticyclonic mesoscale eddies tend to trap more intense STMW than do cyclonic mesoscale eddies. The thickness of STMW, defined by $z_{1}-z_{2}$, can be seen in Fig. $6 \mathrm{~b}$ to correspond well to the observed intensity of STMW. Indeed, the linear correlation coefficient between these two quantities of STMW is 0.94 and is significant at the $99 \%$ confidence level (assuming estimates from individual profiles to be independent). 
Figure 7a shows the potential temperature averaged in the STMW layer:

$$
T_{\text {STMW }}=\frac{1}{z_{1}-z_{2}} \int_{z_{2}}^{z_{1}} T(z) d z .
$$

Unlike the intensity and thickness of STMW, $T_{\text {STMW }}$ is not a sensitive function of geographical location. The mean value of $T_{\text {STMw }}$ from the 108 profiles shown in Fig. $7 \mathrm{a}$ is $17.1^{\circ} \mathrm{C}$ and its standard deviation is only $0.16^{\circ} \mathrm{C}$. To understand this uniformity in $T_{\text {STMw }}$, we plot in Fig. 7b the late-winter (i.e., the second half of March 2004) sea surface temperature distribution. Here, the SST data are derived from the Tropical Rainfall Measuring Mission (TRMM) Microwave Imager (TMI) measurements, which are able to see through clouds with little attenuation (Wentz et al. 2000). The late-winter SST, which approximates well the deepwinter mixed layer temperature, has been found by Stommel (1979) to be preferentially subducted beneath the seasonal thermocline, biasing the $T-S$ properties there to those of the late-winter mixed layer. Indeed, the wide geographical span of late-winter SSTs in the temperature range of $17^{\circ}-18^{\circ} \mathrm{C}$ seen in Fig. $7 \mathrm{~b}$ is the likely cause for the STMW thermostad with the same characteristic temperature (cf. Fig. 4a).

An interesting fact revealed in Fig. $7 \mathrm{~b}$ is that the southern limit of the late-winter $18^{\circ} \mathrm{C}$ isotherm, which corresponds to the upper boundary of STMW, is around $30^{\circ}-31^{\circ} \mathrm{N}$. This implies that in contrast to the recirculation gyre region where $T_{\text {STMW }}$ matches the $l o$ cal late-winter SST values, STMW in the region south of $\sim 30^{\circ} \mathrm{N}$ would have its temperature values colder than the local late-winter SST values. Such a difference across the $30^{\circ} \mathrm{N}$ parallel can clearly be discerned in Fig. 7c. In section $4 \mathrm{~b}$ below it will become clear that the STMW detected south of $30^{\circ} \mathrm{N}$ is not formed locally, but enters the region via lateral induction.

\section{Temporal evolution of STMW}

Repeat profiling measurements of temperature and salinity by the KESS and Japanese Argo floats are used in this section to explore the temporal evolution of STMW. Figure 8 shows the distributions of the STMW intensity based on individual profiles available in each month from June to November 2004. Consistent to what we have found for May 2004 (Fig. 6a), the low-PV signals of STMW tend to be more intense toward the center of the recirculation gyre than along its peripheries. As the cyclonic eddy that was located at $31^{\circ} \mathrm{N}$ and $148^{\circ} \mathrm{E}$ in May moved westward (it is near $142^{\circ} \mathrm{E}$ in October), the weak-PV signals can be seen to persist following its movement. For the "new" cyclonic eddy located at $32^{\circ} \mathrm{N}$ and $147^{\circ} \mathrm{E}$ in October, inspection of the sequential SSH field (not shown) indicates that it originated in the meandering KE jet over the Shatsky Rise in June and propagated subsequently westward as a cut-off, isolated core-core eddy. Given the high-PV value in the cyclonic core of the KE jet (Fig. 5c), it is not surprising to find that the STMW signal inside this eddy is extremely weak.

The synoptic surveys presented in section 3 revealed that the STMW properties are different within the recirculation gyre than farther to the south. In the following, we will examine the STMW evolution in these two regions separately.

\section{a. Recirculation gyre region}

Figure 9 shows the $\theta, S, \sigma_{\theta}$, and $Q$ profiles as a function of time near the center of the recirculation gyre. Here, the time series is constructed by collecting available profiles within a $1^{\circ}$-radius circle centered at $34^{\circ} \mathrm{N}$ and $144^{\circ} \mathrm{E}$. The winter mixed layer observed at this site is deep, exceeding $450 \mathrm{~m}$. Because of the change from cooling to heating in the net surface heat flux forcing, the seasonal thermocline starts to form in mid-April, resulting in a rapid shoaling of the mixed layer (e.g., Qiu and Kelly 1993). Throughout the summer, the surface mixed layer remains shallow, generally $<30 \mathrm{~m}$, and it is not until late September when the net surface heat flux forcing reverses its sign again, that the mixed layer starts to deepen gradually. After mid-April (Fig. 9a), the seasonal thermocline can be seen to form below the mixed layer and deepen as time progresses. It is interesting to note that no corresponding seasonal halocline is formed below the shallow mixed layer. As shown in Fig. 9b, salinity is nearly constant at $\sim 34.8$ psu from the base of the shallow mixed layer to a depth of $400 \mathrm{~m}$. As a result of this constant salinity, evolution of the seasonal pycnocline in the region reflects essentially that of the seasonal thermocline (Fig. 9c).

Because of the abrupt shoaling of the mixed layer, water properties beneath the seasonal pycnocline are clearly seen to be dictated by those that existed in late March. STMW, defined as the layer with $Q<2.0 \times$ $10^{-10} \mathrm{~m}^{-1} \mathrm{~s}^{-1}$, can be seen in Fig. 9d to originate within the deep, late-winter mixed layer. After collapse of the winter mixed layer, the upper boundary of STMW deepens gradually following the thickening of the seasonal pycnocline. The lower boundary of STMW, on the other hand, remains largely at a constant depth of $\sim 500 \mathrm{~m}$.

Figure 10a shows the time series of the STMW intensity $I$ calculated from the PV profiles shown in 

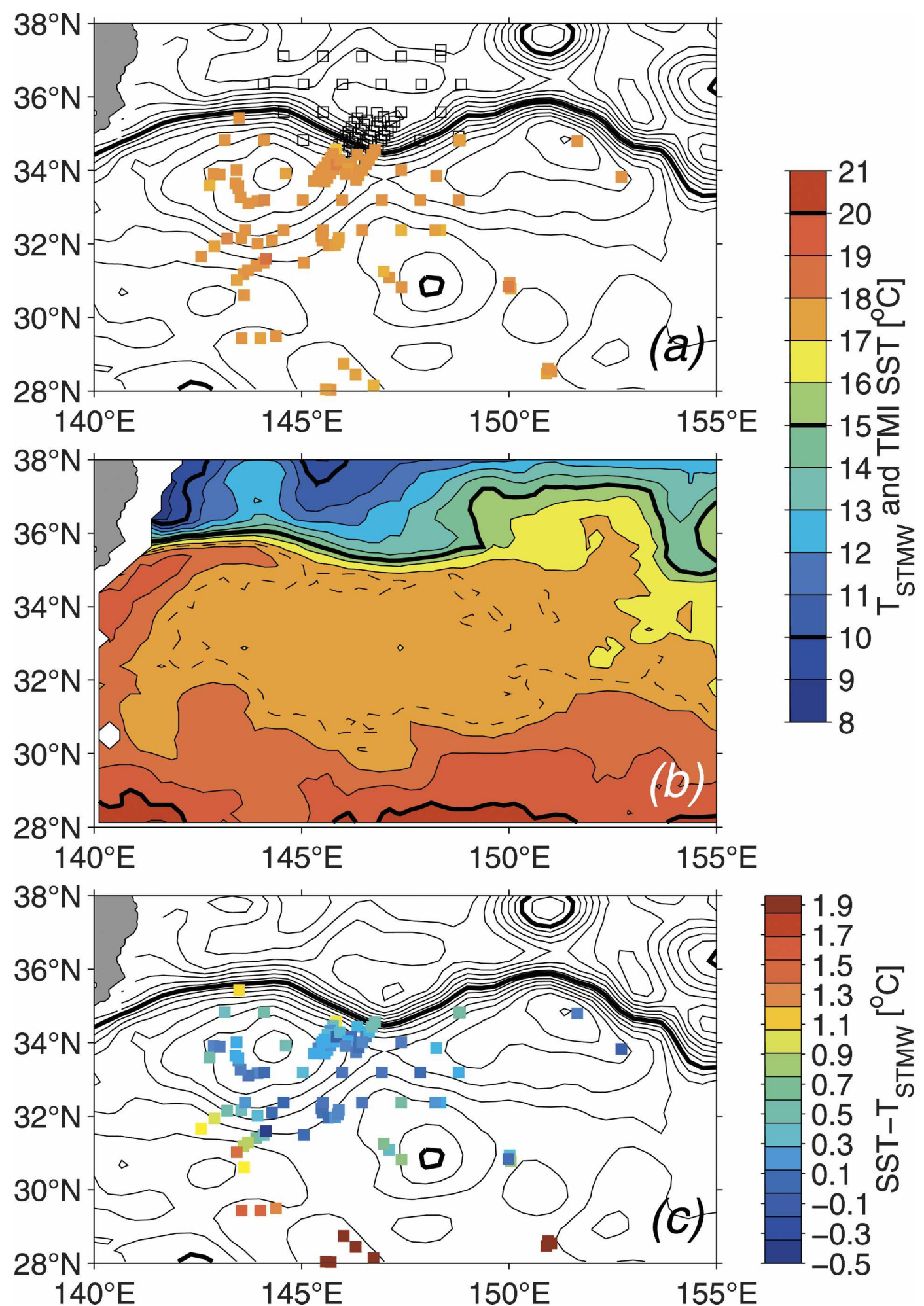

FIG. 7. (a) STMW potential temperature $T_{\text {STMW }}$ estimated from available CTD casts and profiling $T-S$ data in May 2004. Open squares indicate sites where no STMW is detected. (b) TMI SST field in late winter (i.e., the second half of March) of 2004. Dashed lines denote the $17.5^{\circ} \mathrm{C}$ isotherms. (c) Differences between the late-winter SSTs and the $T_{\text {STMw }}$ values. Contours in (a) and (c) indicate the SSH field in May 2004. 

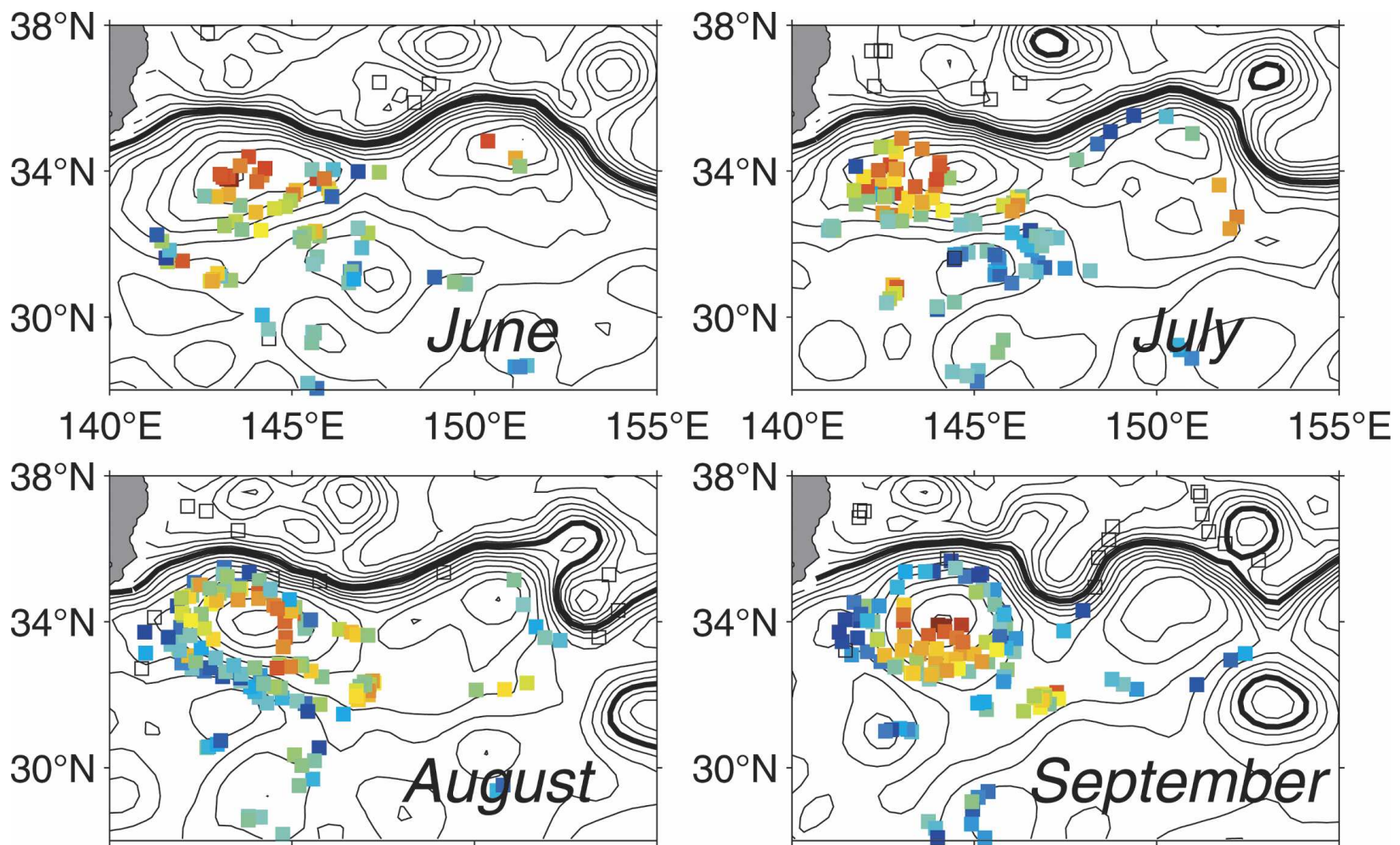

$140^{\circ} \mathrm{E} \quad 145^{\circ} \mathrm{E} \quad 150^{\circ} \mathrm{E} \quad 155^{\circ} \mathrm{E} \quad 140^{\circ} \mathrm{E} \quad 145^{\circ} \mathrm{E} \quad 150^{\circ} \mathrm{E} \quad 155^{\circ} \mathrm{E}$
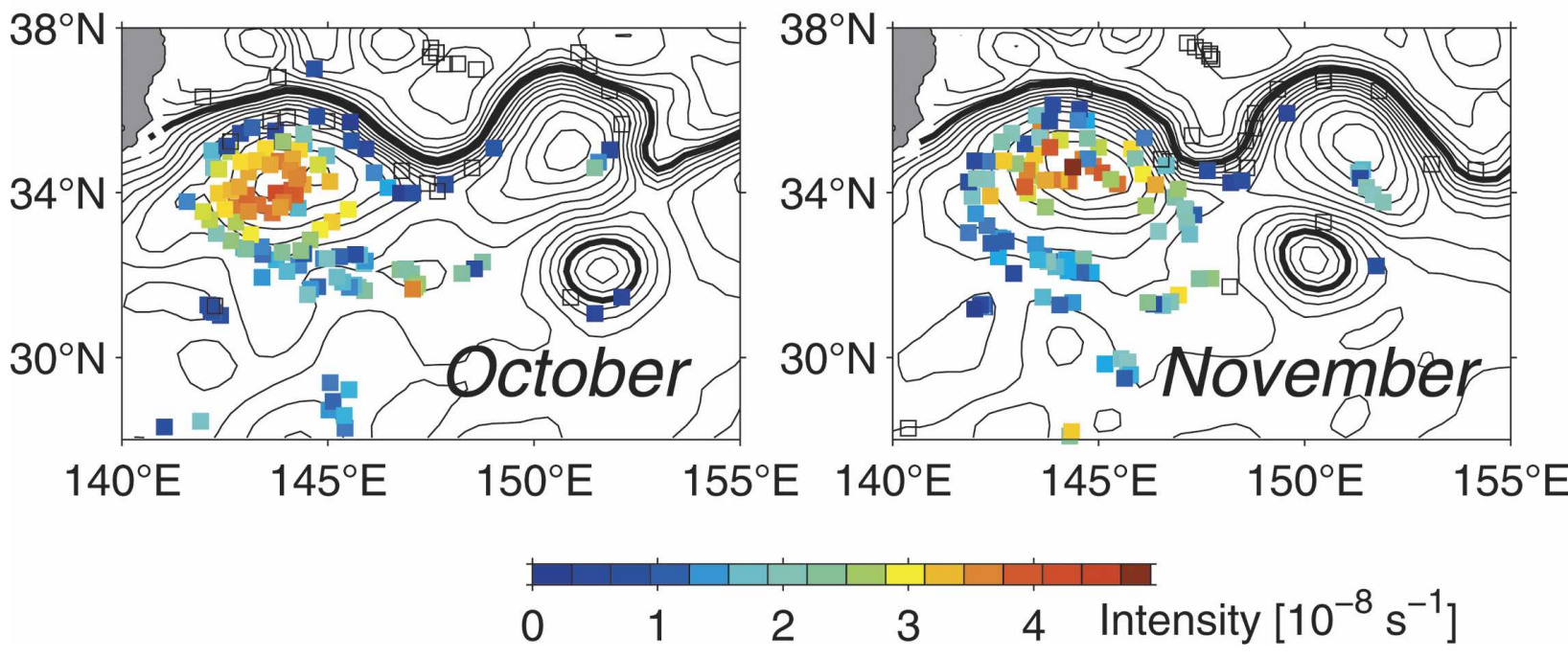

FIG. 8. Intensity of STMW estimated from monthly available profiling $T-S$ data in June-November 2004. Open squares indicate sites where no STMW is detected. Contours indicate the monthly SSH field from satellite altimetry measurements. Contour intervals are 0.1 $\mathrm{m}$, with the thick black lines denoting the $1.7-\mathrm{m}$ contours.

Fig. 9d. In calculating $I$ using Eq. (2), we set the upper boundary for STMW to $z_{1}=0$ if the low-PV water with $Q<2.0 \times 10^{-10} \mathrm{~m}^{-1} \mathrm{~s}^{-1}$ extends to the sea surface. After shoaling of the mixed layer in mid-April, Fig. 10a indicates that the STMW intensity has a general weakening trend from April to July in concurrence with the thickening of the seasonal pycnocline. This trend levels off somewhat after the seasonal pycnocline is fully developed in August-December. The overall reduction in the STMW intensity from late April after the collapse of the winter mixed layer to December is $\sim 55 \%$, from $I \simeq 5.5 \times 10^{-8} \mathrm{~s}^{-1}$ to $2.5 \times 10^{-8} \mathrm{~s}^{-1}$. 

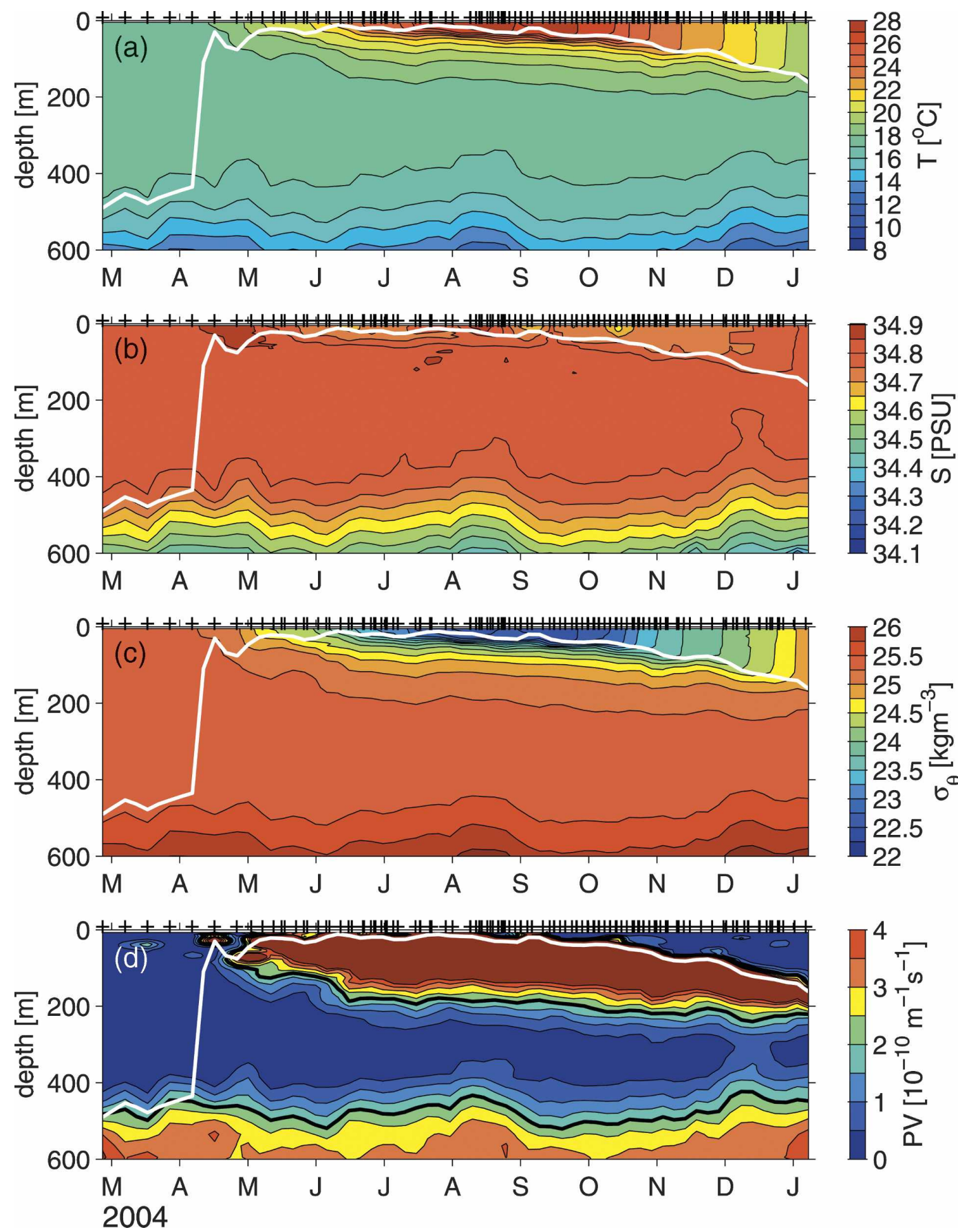

FIG. 9. Time series of (a) potential temperature, (b) salinity, (c) potential density, and (d) potential vorticity within a $1^{\circ}$-radius circle centered at $34^{\circ} \mathrm{N}$ and $144^{\circ} \mathrm{E}$. Crosses at top of each panel indicate the available $T-S$ profiles. White contours denote the mixed later depth, defined as the depth at which $\sigma_{\theta}$ increases by $0.125 \mathrm{~kg} \mathrm{~m}^{-3}$ from its surface value. Thick black lines in (d) indicate the $Q=2 \times 10^{-10} \mathrm{~m}^{-1} \mathrm{~s}^{-1}$ contours.

Notice that this seasonally dependent decline in the STMW intensity cannot be caused by the lateral advection of high-PV water, because the site we have chosen is near the center of the recirculation gyre. Given that the mesoscale eddy activity at the site is observed to be low (see the SSH maps in Figs. 6 and 8), isopycnal eddy diffusion is also not likely to have been an effective contributor. We believe the likely candidate for erosion of STMW is the diapycnal eddy diffusion associated with the development of the sea- 

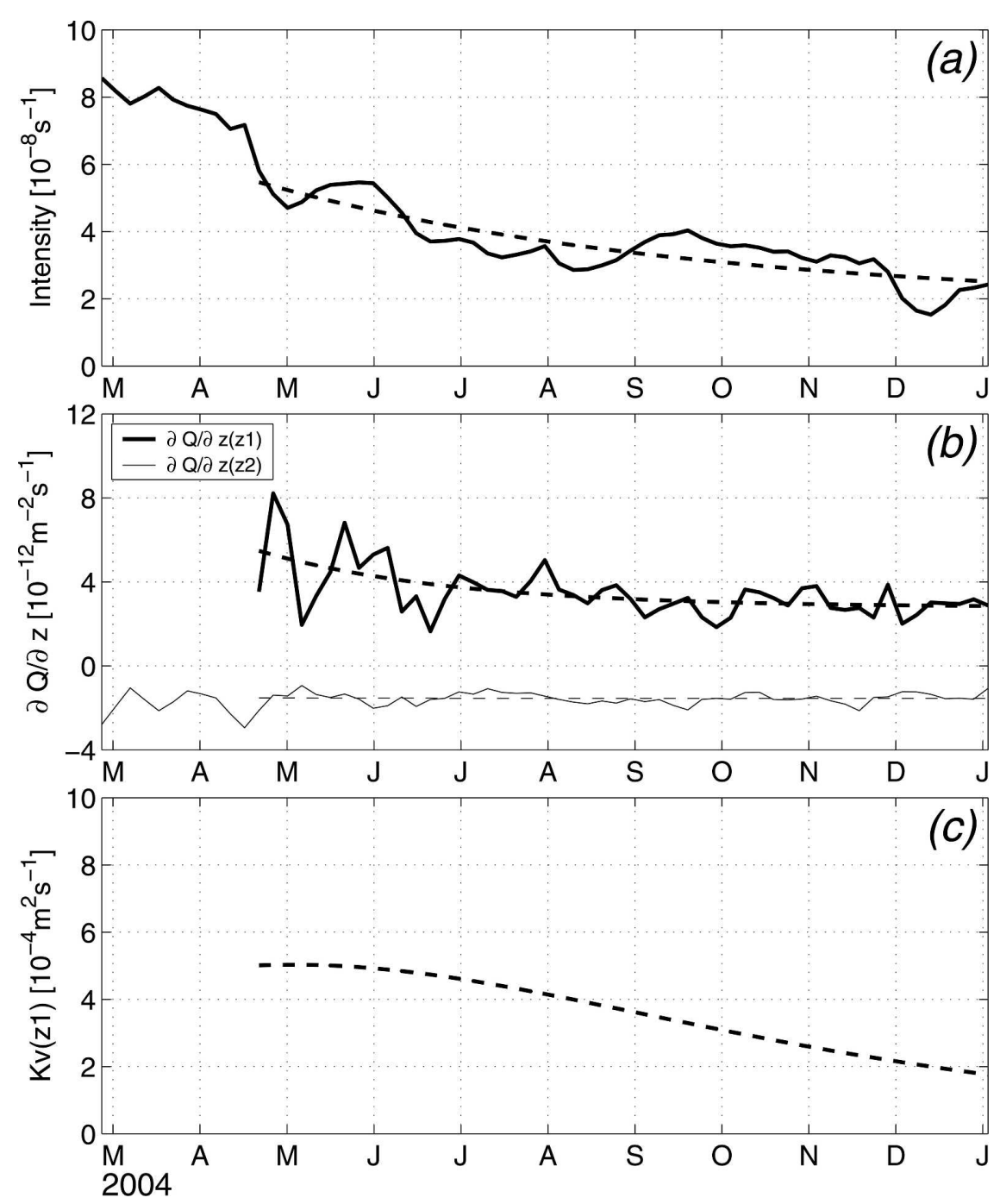

FIG. 10. (a) STMW intensity (solid line) calculated from the profiling data near the center of the recirculation gyre (see Fig. 9). Dashed line is the best fit by $I(t)=A+B \exp [-\gamma(t-$ $\left.t_{o}\right)$ ]. (b) PV gradient at the upper (solid line) and lower (thin line) boundaries of STMW. Dashed lines denote their respective best fit. (c) Diapycnal eddy diffusivity $K_{v}\left(z_{1}\right)$ estimated from Eq. (6).

sonal pycnocline. To quantify the eddy diffusion effect on STMW, let us consider the vertical diffusion equation for PV,

$$
\frac{\partial Q}{\partial t}=\frac{\partial}{\partial z}\left(K_{v} \frac{\partial Q}{\partial z}\right)
$$

where $K_{v}$ is the diapycnal eddy diffusivity, assumed to be a function of time and depth. [For the reasons stated above, horizontal advection and diffusion processes have been excluded from Eq. (4).] From Eq. (2) and Leibniz's rule, we can express the rate of change in the STMW intensity as

$$
\frac{\partial I}{\partial t}=-\int_{z_{2}}^{z_{1}} \frac{\partial Q(z)}{\partial t} d z+\left.\frac{\partial z}{\partial t}\left[Q_{o}-Q(z)\right]\right|_{z_{2}} ^{z_{1}} .
$$

Because $Q=Q_{o}$ at $z=z_{1}$ and $z_{2}$ by definition, the second term on the rhs is zero. Combining Eqs. (4) and (5) in this case leads to

$$
\frac{\partial I}{\partial t}=-K_{v}\left(z_{1}\right) \frac{\partial Q}{\partial z}\left(z_{1}\right)+K_{v}\left(z_{2}\right) \frac{\partial Q}{\partial z}\left(z_{2}\right),
$$

where $\partial Q / \partial z\left(z_{n}\right)$ denotes the vertical PV gradient at depth $z_{n}$. Physically, Eq. (6) states that the temporal change in the STMW intensity is determined by the 
convergence of diffusive PV fluxes through its upper and lower boundaries.

It is worth noting that the lower boundary of STMW $z_{2}$ resides within the permanent thermocline of a subtropical gyre, where previous measurements have consistently found the vertical eddy diffusivity to be around $0.1 \times 10^{-4} \mathrm{~m}^{2} \mathrm{~s}^{-1}$ (e.g., Gregg and Sanford 1980; Ledwell et al. 1993). This low level of vertical eddy diffusivity is consistent with the float measurements, revealing that $\partial Q / \partial z$ at $z=z_{2}$ remained largely a constant throughout the 10-month period of our analysis (see the thin line in Fig. 10b). In contrast, a substantial change in $\partial Q / \partial z$ is observed at the upper boundary of STMW (the thick line in Fig. 10b). Given $K_{v}\left(z_{2}\right)$, Eq. (6) can be used to estimate $K_{v}\left(z_{1}\right)$ inversely. Because only the seasonal erosion of STMW is of our interest, we evaluate $\partial I / \partial t$ by first fitting the time series of $I$ (the solid line in Fig. 10a) to an exponentially decaying function plus a constant: $I(t)=A+B \exp \left[-\gamma\left(t-t_{o}\right)\right]$, where $t_{o}$ is a reference time, chosen here as 20 April when the seasonal pycnocline formed initially (see Fig. 9c). Once $A, B$, and $\gamma$ are determined through least squares fitting [see the dashed line in Fig. 10a for the resultant $I(t)$ time series], $\partial I / \partial t$ is simply given by $-\gamma B \exp \left[-\gamma\left(t-t_{o}\right)\right]$. For consistency, the same functional fitting is applied to the $\partial Q / \partial z$ time series and the results are shown in Fig. 10b by the dashed lines.

Using $K_{v}\left(z_{2}\right)=0.1 \times 10^{-4} \mathrm{~m}^{2} \mathrm{~s}^{-1}$ and the smoothed $\partial I / \partial t$ and $\partial Q / \partial z$ time series, we plot in Fig. 10c the vertical eddy diffusivity $K_{v}\left(z_{1}\right)$ inferred from Eq. (6). From April to August during the developing phase of the seasonal pycnocline, $K_{v}\left(z_{1}\right)$ is found to be in the range of $\sim 4-5 \times 10^{-4} \mathrm{~m}^{2} \mathrm{~s}^{-1}$. The $K_{v}\left(z_{1}\right)$ value is approximately halved during September-December after the seasonal pycnocline becomes fully developed. Notice that the inferred $K_{v}\left(z_{1}\right)$ time series is not sensitive to the chosen value for $K_{v}\left(z_{2}\right)$ because the diffusive PV flux across the upper STMW boundary dominates that across the lower boundary.

The vertical eddy diffusivity inferred above for the upper boundary of STMW is an order of magnitude larger than that observed in the permanent thermocline. One possible cause for this large value may reside in the density structure of STMW itself. Figure 11 shows the typical $\sigma_{\theta}$ profile and its corresponding buoyancy frequency profile observed in the recirculation gyre in June 2004. Here, the buoyancy frequency is given by $N=\left(-g \partial \sigma_{\theta} / \partial z / \rho\right)^{1 / 2}$. Across the base of the seasonal thermocline near the $100-\mathrm{m}$ depth, there exists a significant reduction in $N$ resulting from the presence of the STMW pycnostad. This sharp change in $N$ can pose as a barrier for the downward transmission of internal waves generated in the surface mixed

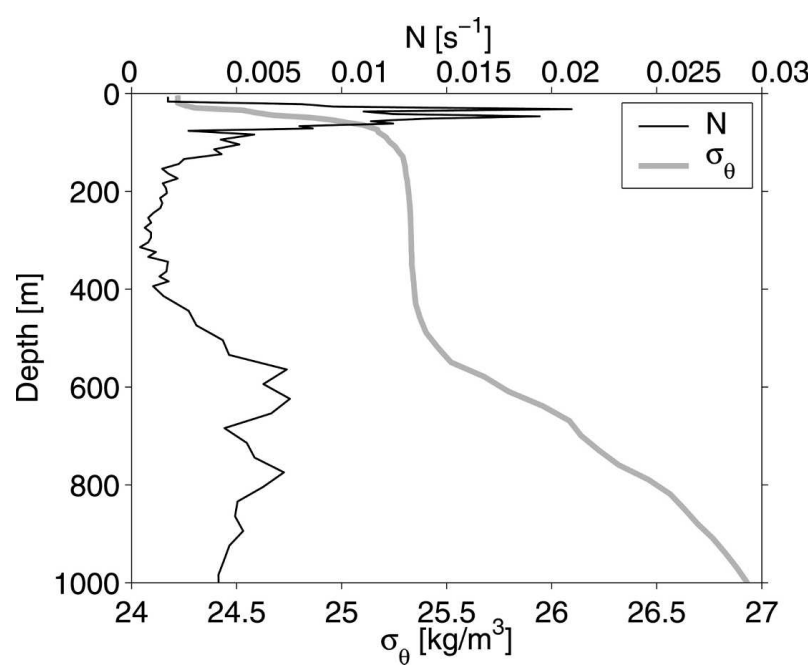

FIG. 11. Vertical profiles of potential density ( $\sigma_{\theta}$, gray line) and buoyancy frequency $(N$, black line) measured by a KESS profiling float on 2 Jun 2004 at $33.77^{\circ} \mathrm{N}$ and $143.34^{\circ} \mathrm{E}$ near the center of the recirculation gyre (see Fig. 8).

layer by atmospheric disturbances (e.g., Gill 1982). By trapping the internal wave energy, this is likely to enhance the local dissipation in the high- $N$ layer of the seasonal thermocline. Investigation into the detailed dissipation mechanisms is beyond the scope of the present study but will be pursued when moored profiler and ADCP data from the KESS project become available.

\section{b. South of the recirculation gyre}

In contrast to the STMW evolution observed in the recirculation gyre, we plot in Fig. 12 the time series of $\theta, S, \sigma_{\theta}$, and $Q$ profiles in a box centered at $29^{\circ} \mathrm{N}$ and $145.5^{\circ} \mathrm{E}$, south of the recirculation gyre. Because fewer $T-S$ profiles are available in the region, the searching box was chosen to be larger than that for Fig. 9, encompassing $27^{\circ}-31^{\circ} \mathrm{N}$ and $143^{\circ}-148^{\circ} \mathrm{E}$. Upper-ocean properties and their temporal evolutions in this southern box differ from those of the recirculation gyre in several qualitative ways.

First, the late-winter mixed layer here is much shallower, extending to $\sim 150 \mathrm{~m}$. The fully developed seasonal pycnocline occupies a layer as thick as $150 \mathrm{~m}$ in summer-fall (see Fig. 12c), implying that much of the water created in late winter and subducted below the spring mixed layer will lose its identity over the seasonal cycle. Indeed, Fig. 12d shows that in the surface $150-\mathrm{m}$ layer, the low-PV signals generated in winter are erased completely by the high-PV signals because of the growth of the seasonal pycnocline. 

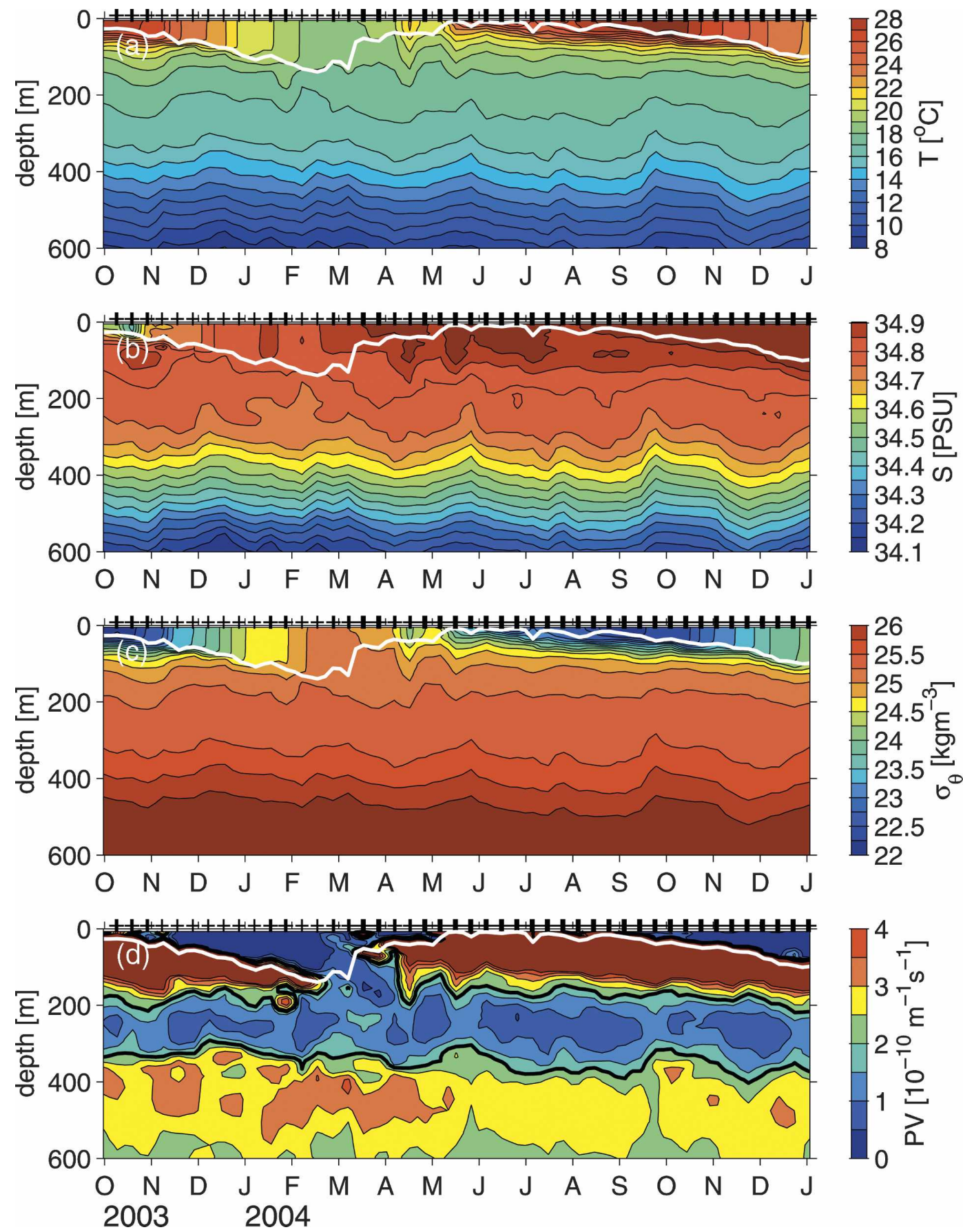

FIG. 12. Time series of (a) potential temperature, (b) salinity, (c) potential density, and (d) potential vorticity within a square of $27^{\circ}-31^{\circ} \mathrm{N}, 143^{\circ}-148^{\circ} \mathrm{E}$. Crosses at top of each panel indicate the available $T-S$ profiles. White contours denote the mixed later depth, defined as the depth at which $\sigma_{\theta}$ increases by $0.125 \mathrm{~kg} \mathrm{~m}^{-3}$ from its surface value. Thick black lines in (d) indicate the $Q=2 \times 10^{-10} \mathrm{~m}^{-1} \mathrm{~s}^{-1}$ contours.

Second, similar to Fig. 9d, there exists a well-defined layer of STMW $\left(Q<2 \times 10^{-11} \mathrm{~m}^{-1} \mathrm{~s}^{-1}\right)$ whose upper and lower boundaries follow roughly the 25.25 and 25.5 $\sigma_{\theta}$ surfaces. In contrast to the recirculation gyre region, however, the $25.25 \sigma_{\theta}$ surface here does not outcrop during the winter in this southern box. Although there is a hint in Fig. 12d that the low-PV signal of the mixed layer is in contact with the underlying STMW from mid-February to early April, it is important to emphasize that these two low-PV waters have different poten- 
tial densities. ${ }^{1}$ Previous studies by Bingham (1992), Huang and Qiu (1994), and Oka and Suga (2003) have noted that STMW formed in the KE recirculation gyre tended to spread south- and southwestward through the process of lateral induction. With the observed $T-S$ properties slightly colder and fresher than those shown in Fig. 9, the STMW detected in the southern box (Fig. 11) most likely originates in the recirculation gyre northeast of the box.

\section{Summary}

Properties and temporal evolution of the North Pacific subtropical mode water are investigated in this study by analyzing the synoptic ADCP and CTD observations and profiling float measurements from the Kuroshio Extension System Study project. Supplemented by the satellite altimetric and Japanese Argo float data, this study has focused on the area of the recirculation gyre associated with the first quasistationary meander of the KE jet. Located where the wintertime heat loss from the ocean to the atmosphere is the largest and where the oceanic anticyclonic circulation is the strongest, this area is one of the preferred sites for the formation of STMW.

Defined as a low-PV water mass with $Q<2 \times 10^{-10}$ $\mathrm{m}^{-1} \mathrm{~s}^{-1}$, STMW in the KE recirculation gyre region was observed to be characterized by a thermostad layer of $16.0^{\circ}-18.0^{\circ} \mathrm{C}$, a halostad layer of $34.70-34.85 \mathrm{psu}$, and a pycnostad layer of 25.2-25.5 $\sigma_{\theta}$. The concurrent, fineresolution CTD and shipboard ADCP measurements from the KESS cruise in May 2004 revealed that the northern edge of STMW extended to within $25 \mathrm{~km}$ of the core of the surface KE jet. This suggests that part of the STMW formed in the upstream KE recirculation gyre can be expected to be advected downstream. Indeed, STMW with similar properties has been observed as far downstream as the date line (e.g., Bingham 1992; Suga et al. 1997; Oka and Suga 2003). The synoptic KESS survey in May 2004 also revealed that STMW was more intense and larger in thickness near the center of the recirculation gyre. The intensity of STMW was generally weaker along the recirculation gyre's edges and within cyclonic mesoscale eddies. Lack of pycnostad in the cyclonic mesoscale eddies stems from the fact that they originate in the KE jet that has a PV value much higher than that in the recirculation gyre.

Repeat float measurements revealed that STMW in the recirculation gyre is a direct product of late-winter

\footnotetext{
${ }^{1}$ This is consistent with the result of Fig. 7 showing that the late-winter SST values south of $30^{\circ}-31^{\circ} \mathrm{N}$ tend to be $\sim 1^{\circ}-2^{\circ} \mathrm{C}$ warmer than the local STMW temperature.
}

convection resulting from the atmospheric cooling and wind forcings. In May 2004, the convection-induced, late-winter mixed layer is observed to reach a depth of $>450 \mathrm{~m}$. After the surface heat forcing changed from cooling to heating in mid-April, the late-winter low-PV mixed layer water was capped from above, forming STMW. Development of the seasonal thermocline, especially during its growing phase from late April to August, is found to contribute significantly to the erosion of STMW. The erosion not only decreases the layer thickness of STMW, it also weakens the vertical PV gradient at its upper boundary. Because the level of mesoscale eddy variability during 2004 was relatively low, much of this erosion is considered in this study as resulting from vertical, small-scale eddy processes accompanying the development of the seasonal thermocline. Determined by the late winter conditions, the lower boundary of STMW, in contrast, shows little seasonal modification in its depth and vertical PV gradient. This observed result for the lower STMW boundary is consistent with the past observations showing that the permanent thermocline layer in a wind-driven subtropical gyre has a low vertical eddy diffusivity on the order of $0.1 \times 10^{-4} \mathrm{~m}^{2} \mathrm{~s}^{-1}$.

As compared with this $K_{v}$ value in the permanent thermocline, we estimated from a PV budget analysis that the vertical eddy diffusivity at the upper boundary of STMW is in the range of $\sim 2-5 \times 10^{-4} \mathrm{~m}^{2} \mathrm{~s}^{-1}$. This enhanced vertical eddy diffusion is closely connected to the growth of the local seasonal thermocline and could be a result of the STMW pycnostad acting as a dynamic barrier for downward-propagating internal waves generated in the surface mixed layer. Because we have attributed the observed erosion of STMW solely to vertical eddy processes, the inferred value for $K_{v}$ should be considered as an upper bound estimate. With the KESS moored profiler and ADCP instruments to be recovered in summer of 2005, future investigations should help to clarify the nature of the eddy processes, including isopycnal eddy mixing (Jayne et al. 1996), that lead to the erosion of STMW.

In contrast to STMW in the recirculation gyre, we found that the STMW detected south of $30^{\circ} \mathrm{N}$ does not form in the local convective mixed layer. The latewinter mixed layer is shallower $(\sim 150 \mathrm{~m})$ in this region than in the recirculation gyre, and following the development of the seasonal thermocline, most of the convectively formed low-PV signals of the late-winter mixed layer are erased. Judging from its $T-S$ properties, the STMW in this region is most likely inducted laterally from the recirculation gyre to the northeast.

Last, we note that 2004 was a year when the KE jet was in a stable state: the southern recirculation gyre was 
well developed and the regional mesoscale eddy activity was suppressed. Both of these conditions favored the formation of an intense STMW. To fully understand the variability of STMW (especially during the period when the KE jet is in an unstable state) and its impact upon the sea surface temperature signals in the region continued observations and analyses are called for.

Acknowledgments. This study benefited from fruitful discussions with Ted Durland, Eric Firing, and Mark Merrifield. Detailed comments made by the anonymous reviewers helped to improve an early version of the manuscript. This study benefited from several global datasets: the merged TOPEX/Poseidon and ERS-1/-2 altimeter data were provided by the CLS Space Oceanography Division as part of the Environment and Climate EU ENACT project, and the TMI SST data were provided by Remote Sensing Systems. The Japanese float data were collected and made freely available by the International Argo Project. In addition, we thank Jules Hummon for assistance processing the ADCP data and the Ocean Data Facility at Scripps Institution of Oceanography, in particular Frank Delahoyde, for the acquisition and processing of the high-quality hydrography measurements. This study was supported by NSF as part of a Collaborative Research Project (OCE0220680 to UH, OCE-0221008 to URI, and OCE0220161 to WHOI).

\section{REFERENCES}

Bingham, F. M., 1992: Formation and spreading of Subtropical Mode Water in the North Pacific. J. Geophys. Res., 97, 11 177-11 189

Deser, C., M. A. Alexander, and M. S. Timlin, 1999: Evidence for a wind-driven intensification of the Kuroshio Current Extension from the 1970s to the 1980s. J. Climate, 12, 1697-1706.

Ducet, N., P.-Y. Le Traon, and G. Reverdin, 2000: Global highresolution mapping of ocean circulation from TOPEX/ Poseidon and ERS-1 and -2. J. Geophys. Res., 105, $19477-$ 19498.

Gill, A. E., 1982: Atmosphere-Ocean Dynamics. Academic Press, $662 \mathrm{pp}$.

Gregg, M. C., and T. B. Sanford, 1980: Signatures of mixing from the Bermuda Slope, the Sargasso Sea and the Gulf Stream. J. Phys. Oceanogr., 10, 105-127.

Hanawa, K., 1987: Interannual variations of the winter-time outcrop area of subtropical mode water in the western North Pacific Ocean. Atmos.-Ocean, 25, 358-374.

— Climate: Observing and Modelling the Global Ocean, G. Siedler, J. Church, and J. Gould, Eds., Academic Press, 373386.

Huang, R.-X., and B. Qiu, 1994: Three-dimensional structure of the wind-driven circulation in the subtropical North Pacific. $J$. Phys. Oceanogr., 24, 1608-1622.

Jayne, S. R., N. G. Hogg, and P. Malanotte-Rizzoli, 1996: Recir- culation gyres forced by a beta-plane jet. J. Phys. Oceanogr., 26, 492-504.

Ledwell, J. R., A. J. Watson, and C. D. Law, 1993: Evidence for slow mixing across the pycnocline from an open-ocean tracerrelease experiment. Nature, 364, 701-703.

Le Traon, P.-Y., and G. Dibarboure, 1999: Mesoscale mapping capabilities of multiple-satellite altimeter missions. J. Atmos. Oceanic Technol., 16, 1208-1223.

Masuzawa, J., 1969: Subtropical mode water. Deep-Sea Res., 16, 463-472.

— 1972: Water characteristics of the North Pacific central region. Kuroshio-Its Physical Aspects, H. Stommel and K. Yoshida, Eds., University of Tokyo Press, 95-127.

Miller, A. J., D. R. Cayan, and W. B. White, 1998: A westwardintensified decadal change in the North Pacific thermocline and gyre-scale circulation. J. Climate, 11, 3112-3127.

Mizuno, K., and W. B. White, 1983: Annual and interannual variability in the Kuroshio Current system. J. Phys. Oceanogr., 13, 1847-1867.

Oka, E., and T. Suga, 2003: Formation region of North Pacific subtropical mode water in the late winter of 2003. Geophys. Res. Lett., 30, 2205, doi:10.1029/2003GL018581.

Qiu, B., 2003: Kuroshio Extension variability and forcing of the Pacific decadal oscillations: Responses and potential feedback. J. Phys. Oceanogr., 33, 2465-2482.

_, and K. A. Kelly, 1993: Upper ocean heat balance in the Kuroshio Extension region. J. Phys. Oceanogr., 23, 2027-2041. , and S. Chen, 2005: Variability of the Kuroshio Extension jet, recirculation gyre, and mesoscale eddies on decadal time scales. J. Phys. Oceanogr., 35, 2090-2103.

_ and - 2006: Decadal variability in the formation of the North Pacific subtropical mode water: Oceanic versus atmospheric control. J. Phys. Oceanogr., in press.

Stommel, H. M., 1979: Determination of water mass properties of water pumped down from the Ekman layer to the geostrophic flow below. Proc. Nat. Acad. Sci. USA, 76, 30513055 .

Suga, T., and K. Hanawa, 1995: The subtropical mode water circulation in the North Pacific. J. Phys. Oceanogr., 25, 958-970. - _ - and Y. Toba, 1989: Subtropical mode water in the $137^{\circ}$ E section. J. Phys. Oceanogr., 19, 1605-1618.

_, Y. Taket, and K. Hanawa, 1997: Thermostad distribution in the North Pacific subtropical gyre: The central mode water and the subtropical mode water. J. Phys. Oceanogr., 27, 140152.

Talley, L. D., 1988: Potential vorticity distribution in the North Pacific. J. Phys. Oceanogr., 18, 89-106.

Teague, W. J., M. J. Carron, and P. J. Hogan, 1990: A comparison between the Generalized Digital Environmental Model and Levitus climatologies. J. Geophys. Res., 95, 7167-7183.

Uehara, H., T. Suga, K. Hanawa, and N. Shikama, 2003: A role of eddies in formation and transport of North Pacific subtropical mode water. Geophys. Res. Lett., 30, 1705, doi:10.1029/ 2003 GL017542.

Wentz, F. J., C. Gentemann, D. Smith, and D. Chelton, 2000: Satellite measurements of sea surface temperature through clouds. Science, 288, 847-850.

Wong, A., G. C. Johnson, and W. B. Owens, 2003: Delayed-mode calibration of autonomous CTD profiling float salinity data by $\theta-S$ climatology. J. Atmos. Oceanic Technol., 20, 308-318.

Yasuda, T., and K. Hanawa, 1997: Decadal changes in the mode waters in the midlatitude North Pacific. J. Phys. Oceanogr., 27, 858-870. 